\title{
Therapeutic Benefit of Intracavitary-interstitial Brachytherapy in Cervical Cancer Patients with Small and Large High-risk Clinical Target Volume
}

\author{
(D) Makbule TAMBAŞ
}

'Department of Radiation Oncology, University of Groningen, University Medical Center Groningen, Groningen-Netherlands

\begin{abstract}
OBJECTIVE
We aimed to investigate the added value of interstitial brachytherapy (IS-BT) over classical intracavitary BT (IC-BT) in terms of target coverage and organ at risk (OAR) sparing among patients for whom an optimal dose distribution could not be provided without IS-ICBT and also to determine if the magnitude advantage provided by IS-BT is similar in patients smaller $\left(<30 \mathrm{~cm}^{3}\right)$ and larger $\left(\geq 30 \mathrm{~cm}^{3}\right)$ high-risk clinical target volume $\left(\mathrm{CTV}_{\mathrm{HR}}\right)$.
\end{abstract}

\section{METHODS}

24 patients treated with IS-ICBT were included in this study. IS-BT was performed 76 of $93 \mathrm{BT}$ fractions. For each patient, two additional IC-BT planning were created: (1) $\mathrm{ICBT}_{\text {Target-focused }}$ plan: The priority was adequate coverage of $\mathrm{CTV}_{\mathrm{HR}}$. Then, the OARs were spared as much as possible. (2) ICBT $\mathrm{OARs}_{\text {focused }}$ plan: The priority was given to the OAR sparing. Then, highest $\mathrm{CTV}_{\mathrm{HR}}$ coverage was tried to achieve within the allowed OAR dose limits. The IS-ICBT plans were compared with these two plans in terms of target coverage and OAR doses.

\section{RESULTS}

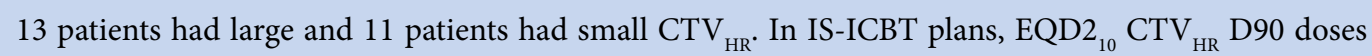
were significantly higher compared with $\mathrm{ICBT}_{\mathrm{OARs} \text {-focused }}$ plans $(\Delta$ dose: $10.5 \pm 6.2 \mathrm{~Gy}, \mathrm{p}<0.001$ ), whereas $\mathrm{EQD} 2{ }_{3} \mathrm{OAR}$ D2cc doses were significantly lower compared with $\mathrm{ICBT}_{\text {Target-focused }}$ plans (Average $\Delta$ dose, bladder: $24.5 \pm 25.9$ Gy [p<0.001], rectum: 7.6 \pm 9.7 Gy [p=0.001], sigmoid: $18.3 \pm 15.3$ Gy $[\mathrm{p}<0.001]$ ). There was no significant difference between patients with small and large $\mathrm{CTV}_{\mathrm{HR}}$ in terms of $\Delta$ doses of both target and OARs.

\section{CONCLUSION}

IS-BT provides significant therapeutic advantage over IC-BT for patients both with small and large $\mathrm{CTV}_{\mathrm{HR}}$.

Keywords: Cervical cancer; CTVHR volume; interstitial brachytherapy; intracavitary brachytherapy.

Copyright $\odot$ 2021, Turkish Society for Radiation Oncology

\section{Introduction}

Combined interstitial intracavitary brachytherapy (ISICBT) has been demonstrated to provide substantial advantage over the traditional intracavitary BT (IC-BT) in terms of target coverage and organ at risk (OAR) doses. [1-3] IS-ICBT is particularly beneficial for patients with a larger high-risk clinical target volume $\left(\mathrm{CTV}_{\mathrm{HR}} ; \geq 30\right.$ $\mathrm{cm}^{3}$ ), extensive parametrial extension, and asymmetric tumor shrinkage after external-beam RT (EBRT).

Due to more flexible and adjustable dose optimization characteristics of interstitial brachytherapy (IS-BT), dose distributions that are similar to patients with smaller $\mathrm{CTV}_{\mathrm{HR}}\left(<30 \mathrm{~cm}^{3}\right)$ can also obtained in pa- 
tients a larger $\mathrm{CTV}_{\mathrm{HR}}$. Moreover, an increase by $10 \%$ in 3 -year local control has been reported in patients with a larger high-risk clinical target volume $\left(\mathrm{CTV}_{\mathrm{HR}} ; \geq 30\right.$ $\mathrm{cm}^{3}$ ) using IS-ICBT, with no increased toxicity.[1]

IS-BT not only facilitates coverage of the parametrial extension of the tumor with an adequate dose, but also accomplishes unacceptable OAR doses due to topography.[4] In our previous study, we have demonstrated the feasibility of the CT-guided needle insertion during combined IS-ICBT in patients with locally advanced cervical cancer using tandem-ovoid Utrecht applicator (Elekta, Veenendaal, The Netherlands). In addition to information provided by magnetic resonance imaging (MRI) in the last week of external-beam radiotherapy $\left(\mathrm{MRI}_{\text {postEBRT }}\right)$, OAR location and positioning of the tandem on the day of BT evaluated in the CT imaging taken after tandem insertion $\left(\mathrm{CT}_{\text {preneedle }}\right)$ was used to determine IS-BT indication, needle channels, and insertion lengths. This method is especially beneficial for patients with smaller $\mathrm{CTV}_{\mathrm{HR}}$, as unexpected indication may emerge based on $\mathrm{CT}_{\text {preneedle }}$ in these patients, whereas IS-BT indication is already determined based on MRI ${ }_{\text {postEBRT }}$ in patients with larger $\mathrm{CTV}_{\mathrm{HR}}$. However, it remains unknown if advantage provided by the IS-BT in patients with smaller $\mathrm{CTV}_{\mathrm{HR}}$ is as great as for those with larger $\mathrm{CTV}_{\mathrm{HR}}$.

Therefore, we aimed to investigate the added value of IS-BT over classical IC-BT in terms of target coverage and OAR sparing among patients for whom an optimal dose distribution could not be provided without IS-ICBT and also determine if the magnitude advantage provided by IS-BT is similar in patients smaller and larger $\mathrm{CTV}_{\mathrm{HR}}$.

\section{Materials and Methods}

\section{Patients and Treatment}

Between May 2018 and January 2020, 74 patients with inoperable cervical cancer were evaluated for BT at Liv Hospital-Ulus Department of Radiation Oncology following EBRT, scheduled at 45-50.4 Gy/25-28 fr, and concomitant weekly cisplatinum $\left(40 \mathrm{mg} / \mathrm{m}^{2}\right)$. Among these, $32 \%(n=24)$ of the patients were treated with IS-BT using the Utrecht applicator, which enabled the study center to be recognized as an IC/IS center based on the definition used in the retroEMBRACE study. [1] The BT was scheduled as 6.5-7.5 Gy in 3-4 fractions based on the EBRT dose. For those 24 patients included in this study, a total of 266 interstitial needles were inserted under CT guidance during 76 of 93 BT fractions. In 17 of these 93 fractions, needle insertion was not indicated.
MRI ${ }_{\text {postEBRT }}$ imaging was performed in the last week of EBRT to evaluate the patient's response and suitability for BT, which was planned within the $1^{\text {st }}$ week after EBRT completion. The patient preparation, clinical workflow, and CT-guided needle insertion were described in detail in our previous study.[5] Briefly, BT was performed under sedoanalgesia. A CT scan was performed after applicator insertion, that is, $\mathrm{CT}_{\text {preneedle }}$. Together with the MRI ${ }_{\text {postEBRT }}$ this scan was evaluated by the radiation oncologist to decide needle indication, channels en insertion lengths. If the IS-BT was indicated based on the tumor extension, applicator position and OAR location on the CT, the needles were inserted on the CT table and a second CT scan was performed after needle insertion $\left(\mathrm{CT}_{\text {postneedle }}\right) \cdot \mathrm{CT}_{\text {preneedle }}$ and $\mathrm{CT}_{\text {postneedle }}$ were used to create BT plans for patients treated with IC-BT and IC-ISBT, respectively.

CT scanning was performed with a $1.25-\mathrm{cm}$ slice thickness using the GEHC Discovery CT750 HD (Waukesha Wisconsin, USA). Three-dimensional BT planning was performed using the Oncentra Brachytherapy Planning System v4.5.3 (Elekta, Veenendaal, The Netherlands) after contouring of the residual gross tumor volume $\left(\mathrm{GTV}_{\mathrm{res}}\right), \mathrm{CTV}_{\mathrm{HR}}$, and OARs, including the bladder, rectum, and sigmoid on the $\mathrm{CT}_{\text {postneedle }}$ [6-9] The plan was initiated by activating all source positions and was continued by manual optimization of the dwell times in the channels of the intrauterine tandem, ovoids, and needles.

All the treatment procedures reported in this study were a part of the routine clinical practice in the institution and were conducted after obtaining consent as relevant. The ethics committee deemed that additional informed consent for this study was not required, based on the Liv Hospital-Ulus Department of Radiation Oncology Medical Research Involving Human Subjects Act. However, all patients were informed that their data could be used for research purposes and that they could refuse consent for such use.

\section{Dosimetry Goals}

The summed biologically equivalent doses in 2-Gy fractions (EQD2) of EBRT and BT were calculated with $\alpha / \beta$ of $10\left(\mathrm{EQD} 2_{10}\right)$ and $3\left(\mathrm{EQD} 2_{3}\right)$ for $\mathrm{CTV}_{\mathrm{HR}}$ and OARs, respectively. The aims and limits of planning in the EMBRACE II protocol were used during plan optimization.[10]

\section{Planning Without Needles}

To determine the advantage provided by ISBT, plans without needles were created in total for the 76 IC-ISBT 
fractions, in which dose optimized was in two different ways (in total 76 fractions * 2 plans $=156$ plans):

1. $\mathrm{ICBT}_{\text {Target-focused }}$ plan: The priority was that $\mathrm{CTV}_{\mathrm{HR}}$ was covered by the minimal dose criteria $\left(\mathrm{CTV}_{\mathrm{HR}}\right.$ D90 >85 Gy) was achieved. Then, the OARs were spared as much as possible. The aim was to determine the IS-BT advantage in terms of OAR sparing when optimal target coverage was maintained

2. ICBT $_{\text {OARs-focused }}$ plan: The priority was given to the OAR sparing. The highest $\mathrm{CTV}_{\mathrm{HR}} \mathrm{D} 90$ was tried to achieve within the allowed OAR dose limits. The aim was to determine the IS-BT advantage in terms of target coverage when OARs sparing was maintained. The EQD2 ${ }_{10}$ dose for CTV ${ }_{\mathrm{HR}}$ D90 and EQD2 3 doses for the $2 \mathrm{cc}$ of the OARs (D2cc) including bladder, rectum, and sigmoid were calculated, and summed with the EBRT EQD2 dose. Eventually, for each of the 24 patients, three different plans were obtained: (1) Plan with needle (IS-ICBT), (2) ICBT $_{\text {Target-focused' }}$ and (3) ICBT $_{\text {OARs-focused }}$.

To determine the benefit of needle use, IS-ICBT plans were compared with these two plans (for target

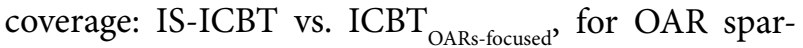
ing: IS-ICBT vs. ICBT OARs-focused $_{\text {. }}$ ). The dose difference ( $\Delta$ dose) between the plans was compared further between patients with small and large $\mathrm{CTV}_{\mathrm{HR}}$ to establish if the advantage of IS-BT was similar between these two patients group.

\section{Statistical Analysis}

The normality of the continuous variables was determined using the Kolmogorov-Smirnov test, and Q-Q plots were checked. Between-group comparisons of continuous variables were performed using the independent t-test and Mann-Whitney U-test for normally and nonnormally distributed variables, respectively. For comparisons between more than two groups, one-way ANOVA and the Kruskal-Wallis test were used for normally and non-normally distributed continuous variables, respectively. Categorical variables were compared using the chi-square test. A two-sided $\mathrm{p} \leq 0.05$ was considered sta- tistically significant. All analyses were performed using the Statistical Package for the Social Sciences (SPSS) for Windows, version 21.0 (SPSS Inc., Chicago, IL, USA).

\section{Results}

For the 24 patients included in this study, a total of 266 interstitial needles were inserted under CT guidance during 76 of $93 \mathrm{BT}$ fractions (three fractions in three patients and four in 21 patients).

The FIGO staging of the patients was as follows: Stages IIA $(n=1)$, IIB $(n=4), \operatorname{IIIB}(n=4), \operatorname{IIIC} 1(n=9$; [T2bN1 $(n=7)$, T3bN1 $(n=2)])$, IIIC2 $(n=2 ;$ [T1b2N1 $(\mathrm{n}=1)$, T2bN1 $(\mathrm{n}=1)])$, IVA $(\mathrm{n}=3$; [T4N0 $(\mathrm{n}=1), \mathrm{T} 4 \mathrm{~N} 1$ $(n=2)])$, and IVB $(n=1 ;$ T3aN1M1). Eleven patients had a small $\mathrm{CTV}_{\mathrm{HR}}$ and 13 had a large $\mathrm{CTV}_{\mathrm{HR}}$.

\section{Needle Dwell Intensities}

The average dwell intensity of an individual needle was $11 \pm 8 \%$ (range, $0-42$ ), and the dwell intensity was $>15 \%$ in 63 out of 266 needles. The total contribution of the needles inserted in a fraction was $37.2 \pm 19.2 \%$ (range, 1.3-84.1). The average contribution of the needles to the complete BT treatment was $30.3 \pm 18 \%$.

\section{The Comparison of the IS-ICBT and IC-BT Plans}

The IS-ICBT plan resulted in a significant increase in EQD2 ${ }_{10} \mathrm{CTV}_{\mathrm{HR}}$ D90 compared with ICBT $_{\text {OARs-focused }}$ plans, with an average of $\Delta$ dose $10.5 \pm 6.2 \mathrm{~Gy}$, which translated into a relative dose increase by $11.9 \% \pm 7.9$ (Table 1, Figs. 1, 2).

The OAR 2cc EQD2 ${ }_{3}$ doses were significantly decreased with the IS-ICBT plans compared to ICBT ${ }_{\text {Tar- }}$ get-focused plans, with an average $\Delta$ dose of $24.5 \pm 25.9 \mathrm{~Gy}$, 7.6 $\pm 9.7 \mathrm{~Gy}$ and $18.3 \pm 15.3 \mathrm{~Gy}$ for bladder, rectum and sigmoid, respectively (Table 1, Figs. 1, 3).

\section{The Comparison of Patients with Small and Large CTV $_{\text {HR }}$}

There was no significant difference between patients with small and large $\mathrm{CTV}_{\mathrm{HR}}$ in terms of $\mathrm{CTV}_{\mathrm{HR}} \mathrm{D} 90$

\begin{tabular}{|c|c|c|c|c|c|}
\hline & IS-ICBT (1) & ICBT $_{\text {Target-focused }}(2)$ & ICBT $_{\text {OARs-focused }}$ (3) & p (1 vs. 2$)$ & p(1 vs. 3$)$ \\
\hline $\mathrm{CTV}_{\mathrm{HR}} \mathrm{D} 90$ (Gy) & $88.2 \pm 3.7$ & $88.2 \pm 3.8$ & $77.7 \pm 7.1$ & 0.558 & $<0.001$ \\
\hline Bladder D2cc (Gy) & $83.6 \pm 7.2$ & $108.1 \pm 29.3$ & $83.4 \pm 7.9$ & $<0.001$ & 0.597 \\
\hline Rectum D2cc (Gy) & $68.0 \pm 7.0$ & $75.5 \pm 10.9$ & $67.8 \pm 6.6$ & 0.001 & 0.640 \\
\hline Sigmoid D2cc (Gy) & $76.8 \pm 8.0$ & $95.0 \pm 19.2$ & $76.6 \pm 9.0$ & $<0.001$ & 0.803 \\
\hline
\end{tabular}

Mean \pm SD values are given. IS-ICBT: Interstitial intracavitary brachytherapy; $C_{T V}$ : High-risk clinical target volume; OAR: Organ at risk; Gy: Gray 
and OAR D2cc values of the IS-ICBT plans. Moreover, these two patient groups were also similar regarding the $\Delta$ dose for both target volume and OARs, that is, the dose difference between IS-ICBT and ICBT plans (Table 2, Figs. 1-3).

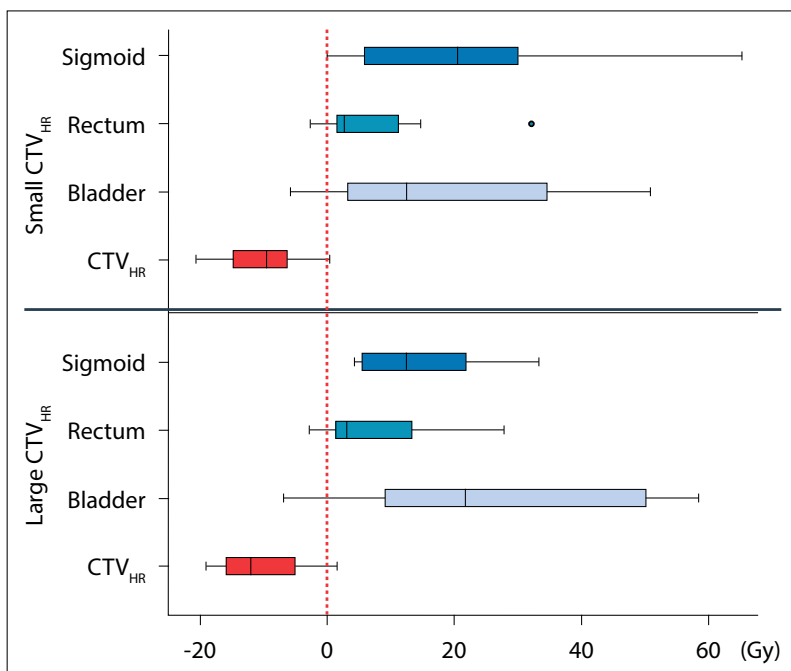

Fig. 1. The dose difference between IS-ICBT and ICBT plans in patients with small and large $\mathrm{CTV}_{\mathrm{HR}}$. ISICBT plans were used as reference plan and compared with ICBT $_{\text {OARs-focused }}$ for $\mathrm{CTV}_{\mathrm{HR}} \mathrm{D} 90$ and $\mathrm{ICBT}_{\text {OARs-focused }}$ for D2cc of bladder, rectum and sigmoid.

IS-ICBT: Interstitial intracavitary brachytherapy; $\mathrm{CTV}_{\mathrm{HR}}$ : High-risk clinical target volume; Gy: Gray.

\section{Discussion}

A large $\mathrm{CTV}_{\mathrm{HR}}$ is regarded as a standard indication for IS-ICBT. However, $46 \%$ of our patients who received IS-ICBT consisted of patients with a small $\mathrm{CTV}_{\mathrm{HR}}$, which was in line with the previous series that reported approximately a frequency of $40 \% \cdot[4,11,12]$ In these patients, asymmetrical extensions of the $\mathrm{CTV}_{\mathrm{HR}}$ in relation to uterus, an OAR located close to the high dose region, larger unilateral target extensions ( $>3.5$ and $>2.5 \mathrm{~cm}$ at vaginal applicator and point A level, respectively) make IS-ICBT necessary.[4,13]

True benefit of the IS-ICBT can be best demonstrated by the comparison of the plans with and without IS-CT in the same patient, rather than comparison of different patient groups or historical controls. Using such an in-patient pairwise comparison, the addition of IS-BT has been shown to increase CTV $\mathrm{HR}_{\mathrm{HR}}$ D90 EQD2 doses by 4-8 Gy on average without a significant increase in the OARs doses.[2,3,11,14] Similar therapeutic advantage was also demonstrated in studies comparing different patient groups. $[4,13,15,16]$ The average $\Delta$ dose between IS-ICBT and ICBT $_{\text {OAR-focused }}$ plan was $10.5 \pm 6.2 \mathrm{~Gy}$, which was consistent between patients with small and large $\mathrm{CTV}_{\mathrm{HR}}$.

A notable characteristic of the current study was that IS-BT effect on both target dose and OARs sparing was evaluated separately, to the best of our knowledge, which was not investigated in the previous studies. The

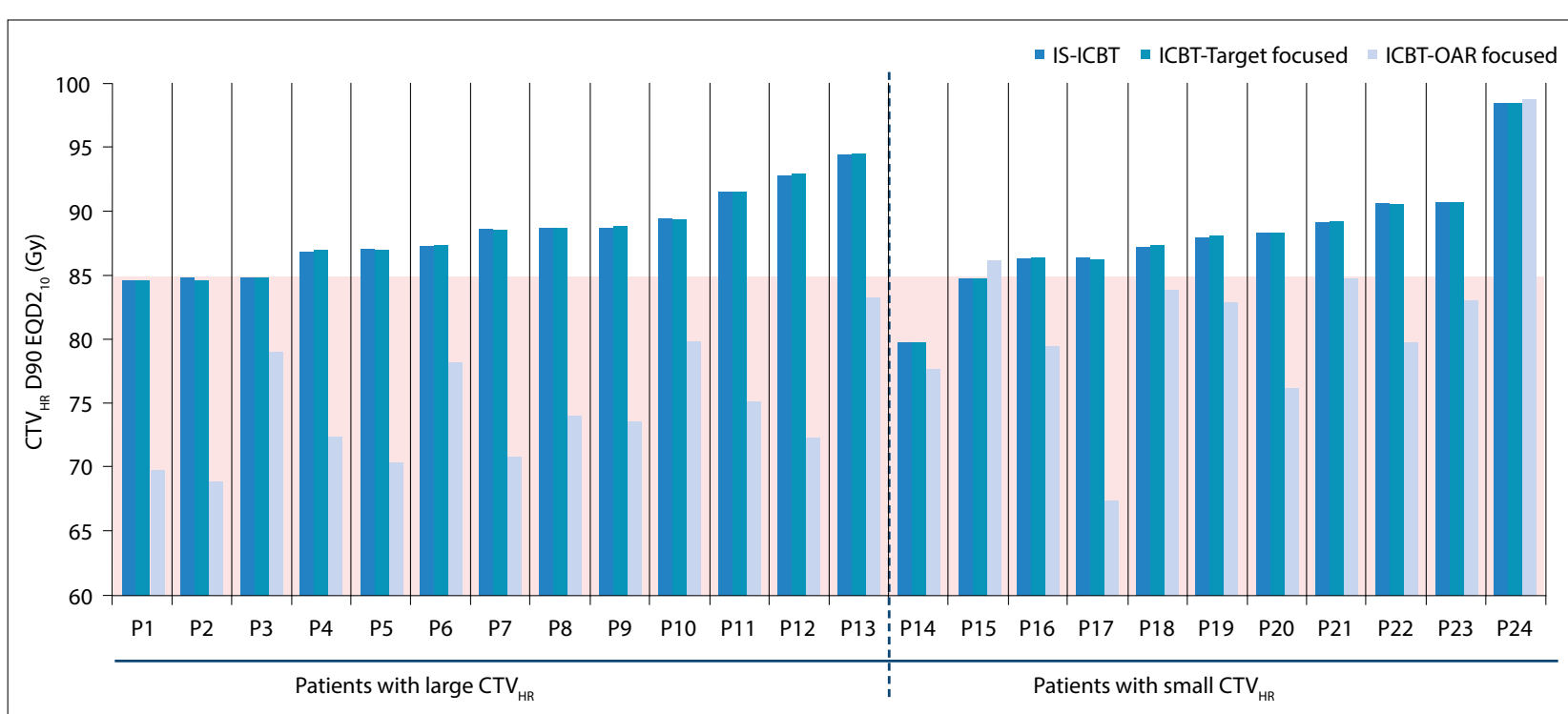

Fig. 2. $\mathrm{CTV}_{\mathrm{HR}} \mathrm{D} 90 \mathrm{EQD} 2_{10}$ doses of the 24 patients included in the study, based on their $\mathrm{CTV}_{\mathrm{HR}}$ volume. Red area indicates the doses which is lower than the minimum criteria for CTVHR D90, that is, 85 Gy. IS-ICBT: Interstitial intracavitary brachytherapy; $\mathrm{CTV}_{\mathrm{HR}}$ : High-risk clinical target volume; OAR: Organ at risk; Gy: Gray. 

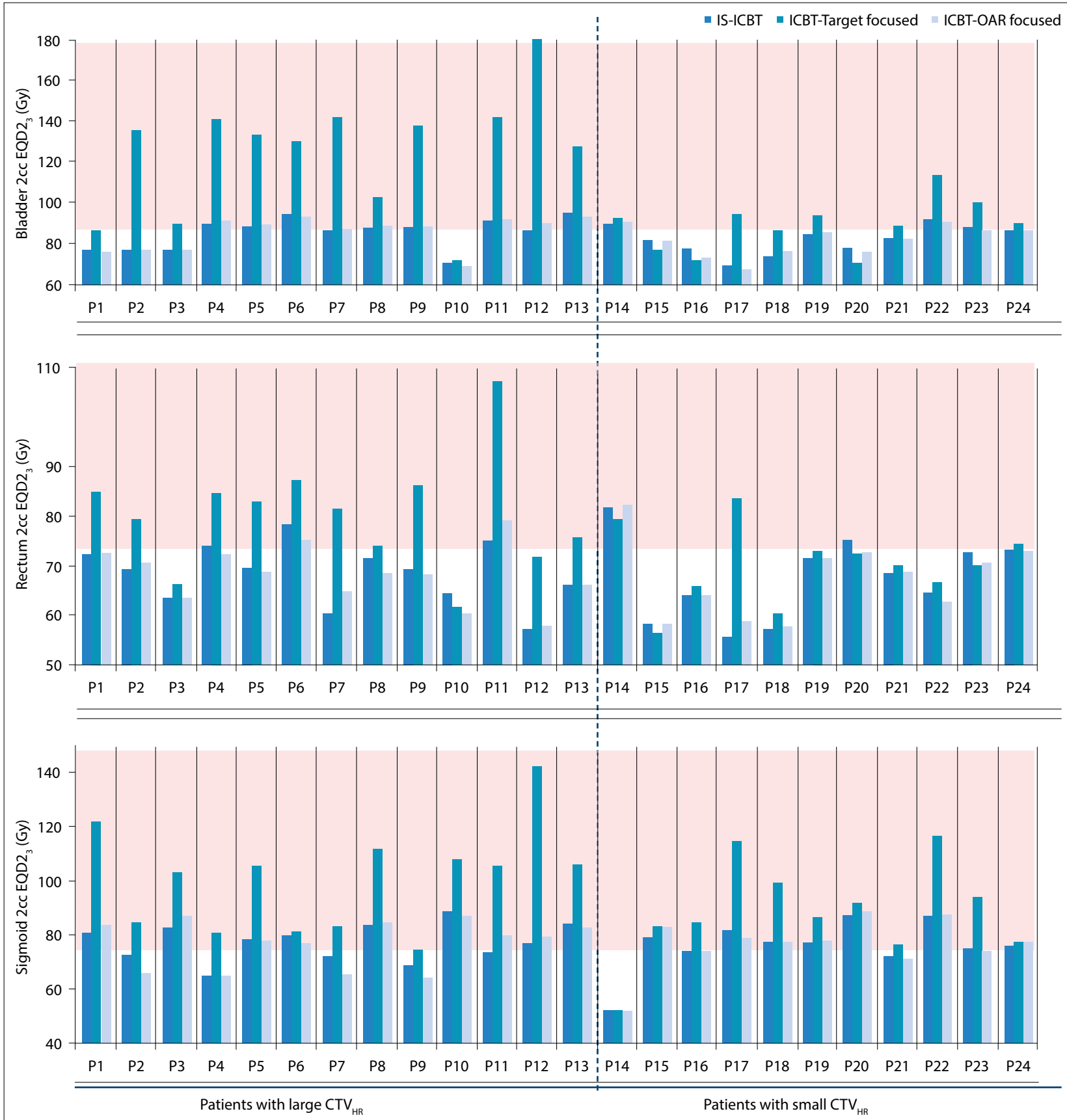

Fig. 3. OAR D2cc EQD23 doses of the 24 patients included in the study, based on their CTVHR volume. Red area indicates the doses which is higher than the maximal allowable dose criteria for that OAR, that is, $90 \mathrm{~Gy}$ for bladder D2cc and 75 Gy for rectum and sigmoid D2cc.

IS-ICBT: Interstitial intracavitary brachytherapy; $\mathrm{CTV}_{\mathrm{HR}}$ : High-risk clinical target volume; OAR: Organ at risk; Gy: Gray.

dose reduction with the IS-BT was remarkable for bladder and sigmoid, with an average $\Delta$ dose of 24 and 18 Gy, respectively. Although non-significant, the sigmoid sparing was even higher in patients with small $\mathrm{CTV}_{\mathrm{HR}}$ compared with those with large $\mathrm{CTV}_{\mathrm{HR}}(21.8 \pm 19.6 \mathrm{~Gy}$ vs. $15.2 \pm 10.1 \mathrm{~Gy})$. These extreme dose differences be- tween with and without IS-BT plans can be explained by more effective use of IS-BT using CT-guidance on the day of treatment after applicator insertion, rather than MRI $_{\text {postEBRT }}$ [5] Considering that 5-10 Gy difference had a clinical effect on tumor control and side effects, based on the evidence from image-guided studies, not only pa- 


\begin{tabular}{|c|c|c|c|}
\hline $\begin{array}{l}\text { Compa } \\
\text { D2cc va }\end{array}$ & $\begin{array}{l}\text { BT doses, } \Delta \text { dose (the } \\
\text { vith small and large } C\end{array}$ & tween IS-ICBT and I & nd OAR \\
\hline & Small CTV $_{\mathrm{HR}}(\mathrm{n}=11)$ & Large $\mathrm{CTV}_{\mathrm{HR}}(\mathrm{n}=13)$ & $\mathbf{p}$ \\
\hline $\mathrm{CTV}_{\mathrm{HR}}$ & $22.0 \pm 5.9 \mathrm{~cm}^{3}$ & $54.4 \pm 22.8 \mathrm{~cm}^{3}$ & $<0.001$ \\
\hline EBRT dose & $49.5 \pm 4.2 \mathrm{~Gy}$ & $50 \pm 4.2 \mathrm{~Gy}$ & 0.773 \\
\hline BT dose per fr & $7.1 \pm 0.7 \mathrm{~Gy}$ & $6.8 \pm 0.6 \mathrm{~Gy}$ & 0.307 \\
\hline $\mathrm{CTV}_{\mathrm{HR}} \mathrm{D} 90$ & $88 \pm 4.8 \mathrm{~Gy}$ & $88.3 \pm 3.1 \mathrm{~Gy}$ & 0.858 \\
\hline Bladder D2cc & $82.2 \pm 7.1 \mathrm{~Gy}$ & $85.1 \pm 7.4 \mathrm{~Gy}$ & 0.370 \\
\hline Rectum D2cc & $66.7 \pm 8.3 \mathrm{~Gy}$ & $68.4 \pm 6.0 \mathrm{~Gy}$ & 0.565 \\
\hline Sigmoid D2cc & $75.1 \pm 9.1 \mathrm{~Gy}$ & $77.3 \pm 6.9 \mathrm{~Gy}$ & 0.507 \\
\hline \multicolumn{4}{|l|}{$\Delta$ dose } \\
\hline $\mathrm{CTV}_{\mathrm{HP}} \mathrm{D} 90^{*}$ & $-9.6(5.8-14.8) \mathrm{Gy}$ & -12.1 (4.8-16.3) Gy & 0.765 \\
\hline Bladder D2cc ${ }^{Y}$ & $12.5(2.9-36.0) \mathrm{Gy}$ & $21.8(7.5-50.6) \mathrm{Gy}$ & 0.543 \\
\hline Rectum D2cc ${ }^{\Upsilon}$ & $2.7(1.3-12.6) \mathrm{Gy}$ & $3.1(0.0-15.2) \mathrm{Gy}$ & 0.931 \\
\hline Sigmoid D2cc ${ }^{\gamma}$ & $20.5(1.5-32.0) \mathrm{Gy}$ & $12.5(5.0-24.4) \mathrm{Gy}$ & 0.303 \\
\hline
\end{tabular}

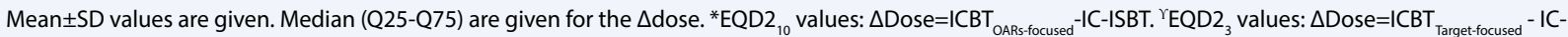
ISBT. IS-ICBT: Interstitial intracavitary brachytherapy; CTV $_{\mathrm{HR}}$ : High-risk clinical target volume; EBRT: external-beam RT; OAR: Organ at risk; Gy: Gray

tients with a large $\mathrm{CTV}_{\mathrm{HR}}$ but also with small $\mathrm{CTV}_{\mathrm{HR}}$ can take a great advantage of IS-BT, when indicated.[17-21]

\section{Limitations of the Study}

Our study has some limitations. First, it is a single center study, which may not precisely reflect the practice in other institution. Second, IS-ICBT plans were the clinical plans used for patient treatment, whereas IC-BT plans were retrospectively created without time pressure. Therefore, even better dose distribution could have been achieved with IS-ICBT plans if they were also created only for research purposes without haste. Third, CT planning was used in this study, whereas results with MRI planning can deviate from our results.

\section{Conclusion}

A considerable proportion of the patient treated with IS-ICBT consists of patients small CTV $\mathrm{HR}_{\mathrm{HR}}(40-45 \%)$. The therapeutic advantage provided by IS-BT was similar between patients with small and large $\mathrm{CTV}_{\mathrm{HR}}$, with regard to better target coverage (10 Gy increase on average) and OARs sparing. Dramatic dose reduction was obtained in sigmoid and bladder using IS-ICBT in both patient groups.

Acknowledgement: I would like to thank Prof.Dr. Merdan Fayda for providing the clinical data and Busra Tavli for creating the brachytherapy plans.

Peer-review: Externally peer-reviewed.

Conflict of Interest: All authors declared no conflict of interest.
Ethics Committee Approval: All the treatment procedures reported in this study were a part of the routine clinical practice in the institution and were conducted after obtaining consent as relevant. The ethics committee deemed that additional informed consent for this study was not required, based on the Liv Hospital-Ulus Department of Radiation Oncology Medical Research Involving Human Subjects Act. However, all patients were informed that their data could be used for research purposes and that they could refuse consent for such use.

Financial Support: None declared.

\section{References}

1. Fokdal L, Sturdza A, Mazeron R, Haie-Meder C, Tan LT, Gillham C, et al. Image guided adaptive brachytherapy with combined intracavitary and interstitial technique improves the therapeutic ratio in locally advanced cervical cancer: Analysis from the retroEMBRACE study. Radiother Oncol 2016;120(3):434-40.

2. Nomden CN, de Leeuw AA, Moerland MA, Roesink JM, Tersteeg RJ, Jurgenliemk-Schulz IM. Clinical use of the Utrecht applicator for combined intracavitary/ interstitial brachytherapy treatment in locally advanced cervical cancer. Int J Radiat Oncol Biol Phys 2012;82(4):1424-30.

3. Jurgenliemk-Schulz IM, Tersteeg RJ, Roesink JM, Bijmolt S, Nomden CN, Moerland MA, et al. MRI-guided treatment-planning optimisation in intracavitary or combined intracavitary/interstitial PDR brachytherapy using tandem ovoid applicators in locally advanced cervical cancer. Radiother Oncol. 2009;93(2):322-30.

4. Kirisits C, Lang S, Dimopoulos J, Berger D, Georg D, Potter R. The Vienna applicator for combined intracav- 
itary and interstitial brachytherapy of cervical cancer: Design, application, treatment planning, and dosimetric results. Int J Radiat Oncol Biol Phys 2006;65(2):624-30.

5. Tambas M, Tavli B, Bilici N, Dizman A, Sertel H, Fayda M. Computed tomography-guided optimization of needle insertion for combined intracavitary/ interstitial brachytherapy with utrecht applicator in locally advanced cervical cancer. Pract Radiat Oncol 2021;11(4):272-81.

6. Haie-Meder C, Potter R, Van Limbergen E, Briot E, De Brabandere M, Dimopoulos J, et al. Recommendations from gynaecological (GYN) GEC-ESTRO working group (I): Concepts and terms in 3D image based 3D treatment planning in cervix cancer brachytherapy with emphasis on MRI assessment of GTV and CTV. Radiother Oncol 2005;74(3):235-45.

7. Potter R, Haie-Meder C, Van Limbergen E, Barillot I, De Brabandere M, Dimopoulos J, et al. Recommendations from gynaecological (GYN) GEC ESTRO working group (II): Concepts and terms in 3D imagebased treatment planning in cervix cancer brachytherapy-3D dose volume parameters and aspects of $3 \mathrm{D}$ image-based anatomy, radiation physics, radiobiology. Radiother Oncol 2006;78(1):67-77.

8. Hellebust TP, Kirisits C, Berger D, Perez-Calatayud J, De Brabandere M, De Leeuw A, et al. Recommendations from gynaecological (GYN) GEC-ESTRO working group: Considerations and pitfalls in commissioning and applicator reconstruction in 3D image-based treatment planning of cervix cancer brachytherapy. Radiother Oncol 2010;96(2):153-60.

9. Dimopoulos JC, Petrow P, Tanderup K, Petric P, Berger $\mathrm{D}$, Kirisits C, et al. Recommendations from gynaecological (GYN) GEC-ESTRO working group (IV): Basic principles and parameters for MR imaging within the frame of image based adaptive cervix cancer brachytherapy. Radiother Oncol 2012;103(1):113-22.

10. Berger T, Seppenwoolde Y, Potter R, Assenholt MS, Lindegaard JC, Nout RA, et al. Importance of technique, target selection, contouring, dose prescription, and dose-planning in external beam radiation therapy for cervical cancer: Evolution of practice from EMBRACE-I to II. Int J Radiat Oncol Biol Phys 2019;104(4):885-94.

11. Fokdal L, Tanderup K, Hokland SB, Rohl L, Pedersen EM, Nielsen SK, et al. Clinical feasibility of combined intracavitary/interstitial brachytherapy in locally advanced cervical cancer employing MRI with a tandem/ring applicator in situ and virtual preplanning of the interstitial component. Radiother Oncol 2013;107(1):63-8.

12. Potter R, Georg P, Dimopoulos JC, Grimm M, Berger $\mathrm{D}, \mathrm{Nesvacil} \mathrm{N}$, et al. Clinical outcome of protocol based image (MRI) guided adaptive brachytherapy com- bined with $3 \mathrm{D}$ conformal radiotherapy with or without chemotherapy in patients with locally advanced cervical cancer. Radiother Oncol 2011;100(1):116-23.

13. Dimopoulos JC, Kirisits C, Petric P, Georg P, Lang S, Berger D, et al. The Vienna applicator for combined intracavitary and interstitial brachytherapy of cervical cancer: Clinical feasibility and preliminary results. Int J Radiat Oncol Biol Phys 2006;66(1):83-90.

14. Otter S, Coates A, Franklin A, Cunningham M, Stewart A. Improving dose delivery by adding interstitial catheters to fixed geometry applicators in high-doserate brachytherapy for cervical cancer. Brachytherapy 2018;17(3):580-6.

15. Nomden CN, de Leeuw AA, Van Limbergen E, de Brabandere M, Nulens A, Nout RA, et al. Multicentre treatment planning study of MRI-guided brachytherapy for cervical cancer: Comparison between tandem-ovoid applicator users. Radiother Oncol 2013;107(1):82-7.

16. Serban M, Kirisits C, de Leeuw A, Potter R, Jurgenliemk-Schulz I, Nesvacil N, et al. Ring versus ovoids and intracavitary versus intracavitary-interstitial applicators in cervical cancer brachytherapy: Results from the EMBRACE I study. Int J Radiat Oncol Biol Phys 2020;106(5):1052-62.

17. Tanderup K, Fokdal LU, Sturdza A, Haie-Meder C, Mazeron R, van Limbergen E, et al. Effect of tumor dose, volume and overall treatment time on local control after radiochemotherapy including MRI guided brachytherapy of locally advanced cervical cancer. Radiother Oncol 2016;120(3):441-6.

18. Mazeron R, Gouy S, Escande A, Dumas I, Del Campo ER, Bentivegna E, et al. Locally advanced cervical cancer: Is it relevant to report image-guided adaptive brachytherapy using point A dose? Brachytherapy 2017;16(4):862-9.

19. Kirchheiner K, Nout RA, Lindegaard JC, HaieMeder C, Mahantshetty U, Segedin B, et al. Doseeffect relationship and risk factors for vaginal stenosis after definitive radio(chemo)therapy with image-guided brachytherapy for locally advanced cervical cancer in the EMBRACE study. Radiother Oncol 2016;118(1):160-6.

20. Manea E, Escande A, Bockel S, Khettab M, Dumas I, Lazarescu I, et al. Risk of late urinary complications following image guided adaptive brachytherapy for locally advanced cervical cancer: Refining bladder dose-volume parameters. Int J Radiat Oncol Biol Phys 2018;101(2):411-20.

21. Spampinato S, Fokdal LU, Potter R, Haie-Meder C, Lindegaard JC, Schmid MP, et al. Risk factors and dose-effects for bladder fistula, bleeding and cystitis after radiotherapy with imaged-guided adaptive brachytherapy for cervical cancer: An EMBRACE analysis. Radiother Oncol 2021;158:312-20. 